\begin{tabular}{l|c|c|c|c|} 
DOI: http://dx.doi.org/10.21276/ap.covid19.2021.10.1.7 \\
Annals of Phytomedicine: An International Journal \\
http://www.ukaazpublications.com/publications/index.php \\
Print ISSN : 2278-9839 Online ISSN : 2393-9885
\end{tabular}

\title{
Applicability of vitamins in the management of COVID-19: An overview
}

\author{
Zoya Shaikh, Priya Sundarrajan*, Lekha Bhagtaney*, Sadaf Zehra**, Kamal Fatima Zahra***, Boubakeur Badra****, Belkis \\ Muca Yigit*****, Nimisha Patel, Hina Alim, Johra Khan******* and Ahmad Ali* \\ Department of Life Sciences, University of Mumbai, Vidyanagari, Santacruz (East), Mumbai-400098, Maharashtra, India \\ *Caius Research Laboratory, St. Xavier's College (Autonomous), 5, Mahapalika Marg, Mumbai-400001, Maharashtra, India \\ **Department of Chemistry and Biochemistry, University of Windsor, Windsor, Ontario N9B3P4, Canada \\ ***Hassan First University, Faculty of Sciences and Techniques, Laboratory of Physical Chemistry of Processes and Materials/Agri-food and \\ Health, B.P. 539, 26000, Settat, Morocco \\ ****Faculty of Nature and Life sciences, Ibn Khaldun University, Tiaret, Algeria \\ *****Vocational School of Technical Sciences, Department of Forestry, Igdir University, Igdir, Turkey \\ ******Department of Medical Laboratory Sciences, College of Applied Medical Sciences, Majmaah University, Majmaah-11952, Saudi \\ Arabia
}

\section{Article Info}

Article history

Received 25 April 2021

Revised 12 June 2021

Accepted 13 June 2021

Published Online 30 June 2021

\section{Keywords}

Antiviral

Coronavirus

COVID-19

Fat soluble vitamins

Immunity

Nutrition

Vitamins (A, B, C, D, E, K)

Water soluble vitamins

\begin{abstract}
The pandemic situation due to COVID-19 has crippled the lives of the whole world population and has affected almost every individual in one way or the other. Researchers have been intrigued due to the increasing number of strains and symptoms. Several approaches have been used to control the spread of this highly infectious disease: early detection of the infected individual, development of a suitable drug and containment of the spread of this virus. Although, several vaccines have been developed, they have shown to have their own limitations and side-effects. One of the measures which has been adopted by the global health agencies is to educate people (infected or uninfected) regarding the maintenance of strong immune system to prevent the infection and lessen the health complications. There are several important factors which determine the immunity of an individual. Eating balanced diet and maintaining the proper supplication of nutritional components are being suggested by health experts to keep the immunity strong. Minerals and vitamins must be maintained in the diet for proper health and immunity. Vitamins have various roles in human physiology. In this review, the relevance of vitamins in the maintenance of immunity has been discussed and reviewed in prevention of adverse health effects of COVID-19.
\end{abstract}

\section{Introduction}

The term "coronavirus" has been derived from Latin corona, which means "crown". Coronaviruses are a family of viruses known as Coronaviridae. It is further classified into the subfamily Coronavirinae and has three genera Alpha coronavirus, Beta coronavirus and Gamma coronavirus. Another subfamily Torovirinae has two genera, Torovirus and Bafinivirus. A total of six species of human coronaviruses have been identified so far, of which one species is subdivided into two strains. Hence, overall seven strains of human coronaviruses exist at present. Coronaviruses possess characteristic spikes which are cup shaped, projecting from their surface (Figure 1). Coronaviruses cause diseases like common cold, Middle East respiratory syndrome (MERS) and severe acute respiratory syndrome (SARS). It causes infection in upper throat, nose, throat windpipe, lungs or sinuses (Almaghaslah et al., 2020).

Corresponding author: Dr. Ahmad Ali

Department of Life Sciences, University of Mumbai, Vidyanagari, Santacruz (East), Mumbai-400098, Maharashtra, India

E-mail: ahmadali@mu.ac.in

Tel.: +91-9870941656

Copyright (C) 2021 Ukaaz Publications. All rights reserved.

Email: ukaaz@yahoo.com; Website: www.ukaazpublications.com
During December 2019, there were reports of an outbreak of pneumonia in Wuhan, China. Thereafter, a novel strain of coronavirus, was traced which was named as 2019-nCoV by the World Health Organization (WHO). Later, the International Committee on Taxonomy of Viruses renamed it as SARS-CoV. The strain obtained in Wuhan is identified as a new Beta coronavirus strain. Also, it is genetically similar (70\%) to SARS-CoV. Bats are suspected to be the origin of this virus as it has a similarity of $96 \%$ to bat coronavirus (Cohen, 2020; Hui et al., 2020). This rapidly spreading coronavirus disease was declared as COVID-19 by the WHO on February $11^{\text {th }}, 2020$. Individuals who were infected initially were supposedly exposed to the seafood market in Wuhan. The novel strain of coronavirus (2019 n CoV) was announced as the causative agent by the Chinese authorities (Backer et al., 2020; van Regenmortel et al., 2000).

In March 2020, COVID-19 outbreak was declared as a pandemic by the World Health Organization (WHO). It triggers respiratory tract infection and spreads due to person-to-person contact. Fever, coughing, shortness of breath, trouble breathing, fatigue, chills, body aches, headache, sore throat, congestion/runny nose, loss of smell or taste, nausea, and diarrhoea are the main symptoms of COVID-19. The virus can also lead to respiratory failure, pneumonia, heart 
problems, septic shock, and death. The cytokine release syndrome or a cytokine storm can further complicate the case of COVID-19. It is a condition in which the immune system is triggered by an infection and the bloodstream is flooded by cytokines (inflammatory proteins) that can further lead to organ failure (McIntosh et al., 2020).

Coronaviruses are large spherical particles having unique surface projections (Figure 1). Their diameter ranges from 80 to $120 \mathrm{~nm}$ and molecular weight is around $40,000 \mathrm{kDa}$. The envelope (E), membrane $(\mathrm{M})$, and spike (S) structural proteins are anchored in the viral envelope, which is made up of a lipid bilayer. Approximately 74 surface spikes are present on a coronavirus (Bhat et al., 2021; Lalchhandama, 2020). Coronaviruses are zoonotic (Paramanya et al., 2021). It means that they get transmitted between humans and animals. Previously, identified coronavirus includes MERS-CoV and SARS-CoV. MERS-CoV causes Middle East respiratory syndrome. It was transmitted to humans from dromedary camels. SARS-CoV causes severe acute respiratory syndrome, transmitted to humans from civet cats. COVID-19 seems to be zoonotically transmitted from a wet market in Wuhan (Organization, 2020b).

Some other common human coronaviruses are NL63, 229E, HKU1 and OC43. They cause cough, runny nose, sore throat and moderate upper respiratory tract symptoms (mild to moderate). These viruses spread via air due to sneezing, coughing or close contact of infected person (Organization, 2020a). Strategies for the prevention of COVID19 include hand hygiene, isolation of infected persons, use of potential protective equipment and proper ventilation. Since COVID-19 spreads via large droplets that are produced due to sneezing and coughing of symptomatic individuals, it can occur in all age groups. Although, asymptomatic individuals can also transmit it before the symptoms appear as they get infected (Escher, 2020).

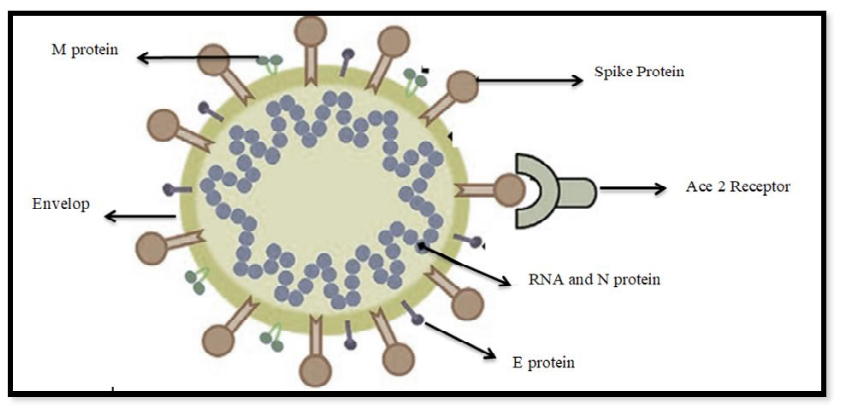

Figure 1: Structure of coronavirus (Adapted from Amin and Jha, 2020 ).

Various approaches have been used to prevent the adverse health effects of COVID-19. This includes rapid identification, containment and proper medication. Global health agencies and health experts have also advised people to maintain strong immunity by having proper diet and having supplication of essential nutritional requirements like water, minerals and vitamins.

\section{Vitamins and their antiviral and therapeutic properties}

Vitamins are known as organic compounds needed in minor quantities for maintenance of optimum growth and health in human beings. A strong immune system is important to protect an individual against the susceptibility and severity of viral infections. The innate immune system is the first line of defence against any infection. When infections are caused due to viruses, the first line of defence is the innate immune system which acts by preventing the replication of viruses, boosting the clearance of viruses, facilitating tissue repair and triggering the adaptive immune response. A higher incidence of viral infections is observed in individuals with vitamin deficiency (Gorji and Ghadiri, 2020).

Vitamins can be classified into two major groups, those which are soluble in fats, namely; vitamins A, D, E and $\mathrm{K}$ and those which are soluble in water, namely; vitamin B complex and C. The structures of fat-soluble vitamins are isoprenoid compounds consisting of isoprene units. The storage of vitamins that are soluble in fats takes place in liver and adipose tissue and these vitamins are not readily excreted in the urine. Therefore, their excess consumption, specifically A and D, may lead to accumulation and toxicity. Water-soluble vitamins are a heterogeneous group of compounds since they vary in structures. These vitamins are usually readily excreted from the urine and, hence are not toxic to the body. With an exception of B12, these vitamins are not stored in the body and are continuously required in the diet (Gorji and Ghadiri, 2020).

\subsection{Vitamin A}

Vitamin Ais essential for maintaining vision as it is the visual pigment of the eye, encouraging growth and development by acting as a hormone and protecting the body's mucosal and epithelial integrity (Jayawardena et al., 2020). Retinoic acid, a derivative of vitamin A helps in the development of epithelial tissue by regulating its gene expression. Thus, retinoic acid is also used as an active ingredient in drugs used for the treatment of acne and wrinkled skin. Retinal is another derivative of vitamin A present as a pigment in the rods and cones of the retina. In response to light, this pigment is responsible for the production of a neuronal signal in the brain. Some food sources rich in vitamin A are fish liver oils, eggs, whole milk and butter. Carotene, a pigment that is usually found in carrots, sweet potatoes and other vegetables can be enzymatically converted into vitamin A in humans. Vitamin A deficiency usually leads to night blindness, retarded growth and development, dryness of skin, mucous membranes and eyes (Nelson et al., 2008).

Vitamin A also plays a significant role in the immune system. Vitamin A plays a major role in improving the function of the immune system and also in the regulation of cellular and humoral immune response. In infants, supplementation with vitamin A has significantly improved the response to antibodies after administration of certain vaccines such as antirabies and measles (Jayawardena et al., 2020). A deficiency in vitamin A causes a decrease in thymus weight, decreased proliferation of lymphocytes, diminished T-cell mediated response and increased adherence of pathogens to epithelial tissues found in the respiratory tract. In viral infections, vitamin A acts by inhibiting the replication of the virus, encouraging immune response and also in a few viral infections decreasing the morbidity and mortality. For instance, in measles and human immunodeficiency virus (HIV), the decrease in the morbidity and mortality could be because of an improved antibody production and proliferation of lymphocytes in addition to an increase in the production of T-cells. Many studies have also reported the significance of vitamin A in regulating the immune responses in case of mucosal infections(Gorji and Ghadiri, 2020).

\subsection{Vitamin B complex group}

The group of vitamin B complex composes of a total of eight vitamins namely, B1 (Thiamine), B2 (Riboflavin), B3 (Niacin), B5 (Pantothenic 
acid), B6 (Pyridoxine), B7 (Biotin), B9 (Folic acid), and B12 (Cyanocobalamin). In the body, this group of vitamins play a very important role as coenzymes for various enzymes associated with metabolic pathways. Their functions include transporting oxygen and nutrients rich in energy throughout the body, releasing energy from carbohydrate and fat and breaking down amino acids. Some good sources of B vitamins are milk, eggs, meat, beets, spinach, fish, whole grains and cereals, banana, yeast, etc. (Nelson et al., 2008).

$\mathrm{B}$ vitamins have a strong association with immune responses of the host towards infections. Energy generation in a variety of immune cells is maintained by the vitamins B1, B2 and B5 which have effects on the immune response of the host. There have been reports that suggest that patients suffering from HIV have high prevalence of deficiency in vitamin B1. An antiviral effect of vitamin B2 is observed in viruses such as Middle East respiratory syndrome-related coronavirus (MERS-CoV), alone or in combination with ultraviolet light. People having deficiencies in vitamins B6, B9, and B12 are found to have increased susceptibility to respiratory infections caused by viruses such as influenza. A significant antiviral effect such as regulation of transcription and replication of RNA viruses such as coronavirus is brought about by the conjugate analogue of vitamin A-vitamin B6 (Gorji and Ghadiri, 2020).

\subsection{Vitamin C}

Vitamin $\mathrm{C}$ or ascorbic acid resembles monosaccharides in structure and is a derivative of hexose. Ascorbic acid also shows presence of enolic hydroxyl groups that imparts the acidic nature. It is a strong reducing agent. The proven physiological activities of vitamin $\mathrm{C}$ are attributed to its main chemical property of reversible oxidation to semi-dehydro-L-ascorbic acid and subsequent oxidation to dehydroL-ascorbic acid (Abobaker et al., 2020). Some rich sources of vitamin $\mathrm{C}$ are citrus fruits, guava, tomatoes and potatoes.

Deficiency in vitamin $\mathrm{C}$ causes a condition known as scurvy. Because of scurvy, there is often an observation of increased susceptibility to infections specifically of the respiratory tract. However, administration of this vitamin to patients suffering from acute respiratory infections can reduce the risk of severe respiratory symptoms (CorreaRodríguez et al., 2020). Vitamin C has significantly beneficial effects on the immune system like enhancing the production, migration and functions of immune cells, thereby improving in serum the levels of complement proteins and antibodies. Along with this, vitamin $\mathrm{C}$ also helps in lymphocyte differentiation and proliferation and improves the production of type-1 interferon (IFN). Vitamin C triggers the immune response against the influenza virus by improving the production of IFN-IL-1-1 $\alpha / \beta$. Many reports also indicate that high doses of vitamin $\mathrm{C}$ can have direct viral elimination effects (Gorji and Ghadiri, 2020). Vitamin C also has direct antiviral mechanisms where it can damage the viral capsid and inhibit viral replication. The antioxidant properties of vitamin $\mathrm{C}$ are helpful in preventing the damage caused to host cells due to oxidative stress. This property is even more important in case of critically high oxidative stress observed in diseases like COVID-19 and acute respiratory distress syndrome (ARDS) (Correa-Rodríguez et al., 2020).

Research on the clinical applications of vitamin $\mathrm{C}$ is progressing rapidly. This molecule is very effective as an antioxidant that helps fight infections, cardiac disorders and cancer. Due to its immunomodulatory properties, the efficacy of vitamin $\mathrm{C}$ against microbial infection, sepsis, and biofilm has also been proven. And also at very high levels, vitamin $\mathrm{C}$ is both safe and non-toxic. It is involved in numerous biological mechanisms, the majority of which are related to immune function. It is also known to contribute to the immune defense by directly promoting and boosting various cellular capacities of the primitive and adaptive immune system. A critical dose of vitamin $\mathrm{C}$ is crucial for a natural and operational host protection process. It can effectively stimulate the secretion of more distinct interleukin (IL)-12 by dendritic cells and activate T and B cell functions (Abobaker et al., 2020). Clinically, administration of vitamin $\mathrm{C}$ to healthy individuals improved and reinforced natural $\mathrm{K}$ cell activity, proliferative lymphocytes and chemotaxis (Bauer et al., 2020).

The reliability of vitamin $\mathrm{C}$ use for viral infectious diseases has already been the subject of numerous extensive studies, where some of these studies confirmed that high doses of vitamin $\mathrm{C}$ could have significant antiviral effects. Thus, it has been proven that vitamin $\mathrm{C}$, in sufficient quantities, could reduce the incidence and severity of colds and related respiratory infections (Pauling, 1971). Another in vitro study revealed that four out of five suspended viruses were effectively inactivated within 24 hours by high doses of vitamin C, combined with free copper and/or iron. In a separate study, the rabies virus completely lost its infectivity after 72 hours of exposure to ascorbic acid (Abobaker et al., 2020).

It was revealed that the replication of three different types of viruses: HSV-1 (family Herpesviridae), influenza virus type A (family Orthomyxoviridae) and PV-1 (family Picornaviridae) were blocked by vitamin C (Furuya et al., 2008). They reported that the antiviral activity of vitamin $\mathrm{C}$ is not virus-specific; the multiplication of very different virus structures is inhibited, independently of the doublestranded DNA or single-stranded RNA genome. enveloped or nonenveloped, and independently of the replication site and viral genome transcription inside the infected cells. A study has shown that vitamin $\mathrm{C}$ in combination with red ginseng may have antiviral effects by activating immune cells as well as T-cells and the inhibition of the gene expression of the viral lytic cycle in influenza-infected Gulo (/-) mice (Kim et al., 2016). Influenza viruses and coronaviruses $\left(\mathrm{H}_{5} \mathrm{~N}_{1}\right.$, $\mathrm{H}_{1} \mathrm{~N}_{1}$, Severe Acute Respiratory Syndrome Coronavirus and Middle East Respiratory Syndrome Coronavirus) are fatal infectious agents recognized to provoke lung injury and death due to acute respiratory distress syndrome (ARDS). Another study described the effective use of vitamin $\mathrm{C}$ at high-dose intravenous as an interventional therapy for acute respiratory distress syndrome (ARDS) resulting from respiratory enterovirus/rhinovirus infections (Fowler III et al., 2017).

\subsection{Vitamin D}

The structure of calciferol (vitamin D) resembles that of sterols and functions like a hormone. Vitamin D2 (ergocalciferol) and vitamin D3 (cholecalciferol) are the two main forms of vitamin D. The D2 form of vitamin D is produced commercially using ergosterol present in yeast. Vitamin D2 is added as a supplement in milk and butter. Whereas, vitamin D3 is produced in the skin from the compound 7dehydrocholesterol which is converted by the UV component of the sunlight. Vitamin $\mathrm{D}_{3}$ itself is not biologically active, but is enzymatically transformed in the liver and kidney into 1,25dihydroxycholecalciferol (a hormone) which plays an important role in the absorption of calcium in the intestine, kidney and bones. Some conditions caused due to vitamin D deficiency are defective bone formation and rickets, the cure for which is in administration of the 
vitamin. Fatty fish, fish liver oils, egg yolk, mushrooms, etc., are a few good dietary sources of vitamin D. Exposure of skin to sunlight and fortified foods also good sources of vitamin D (Nelson et al., 2008).

The responses of the immune system both adaptive and innate are regulated by vitamin D. Epidemiological studies suggest that the rise in susceptibility to acute respiratory viral infections may be linked to deficiency in vitamin D (Jayawardena et al., 2020). The effects of vitamin $\mathrm{D}$ on the immune system include differentiating the precursors of monocytes to macrophages, downregulating the tolllike receptors in monocytes (TLR-2 and TLR-4), reduction in the responses to inflammation and, thereby preventing the tissue damage due to excessive inflammation. On intake of exogenous vitamin $\mathrm{D}$, it is observed that rhinovirus replication is inhibited in the bronchial epithelial cells, the cause which could be due to activation of IFN innate immune system. This IFN pathway is known to drive the expression of genes involved in viral clearance, displays inherent activity against viruses and is also involved in further activation of adaptive immune response. There have also been reports that indicate that, if the patients are deficient in vitamin $\mathrm{D}$, a greater severity in illness, dysfunction of multiple organs and higher mortality in patients that are critically ill is seen specifically in case of sepsis and pneumonia. The high risk of mortality may be greatly reduced, if the patients are supplemented with vitamin D. The administration of inactivated influenza virus coapplied with vitamin D have shown a rise in antibody response to the hemagglutinin of the virus as well as an improvement in mucosal immunity (Gorji and Ghadiri, 2020).

\subsection{Vitamin $\mathrm{E}$}

The structure of vitamin $\mathrm{E}$ or tocopherols constitute an aromatic ring and a long side chain of isoprenoids. Vitamin $\mathrm{E}$ being hydrophobic in nature, most of their function is associated with lipoproteins present in the blood, lipid deposits and cell membranes. The aromatic ring of tocopherols interacts with the radicals of reactive oxygen and destroys them, thereby acting as biological antioxidants. Unsaturated fatty acids are prevented from undergoing oxidation and protect the cell fragility which is caused by oxidative damage to membrane lipids. Vitamin E is present in vegetable oils and eggs and is particularly abundant in wheat germ. In humans, vitamin E deficiency is very rare and is defined by fragile erythrocytes (Nelson et al., 2008).

In the immune system, vitamin E maintains the coherence of the epithelial membranes resulting in enhanced interleukin-2 (IL-2) production, the action of natural killer (NK) cells, the functions mediated by T-cells and the proliferation of lymphocytes. In humans and aged mice infected with influenza virus, a rise in the proliferation of lymphocytes and in the production of IL- 2 and IFN- $\gamma$ was observed on administration of vitamin E. A combination of selenium and vitamin $\mathrm{E}$ can control the replication of the virus as well as its mutation. However, in case of deficiency of these micronutrients the RNA viruses can convert into more virulent strains. A significant reduction in the vitamin $\mathrm{E}$ levels of plasma was observed in patients with ARDS who were admitted to the ICU. Administration of the vitamins $\mathrm{E}$ and $\mathrm{C}$ reduced the stay of patients inflicted with ARDS and pneumonia in the ICU (Gorji and Ghadiri, 2020).

\subsection{Vitamin K}

Vitamin $\mathrm{K}$ has a specific coenzyme function. It is required for the production of blood clotting factors which are significant for coagulation. Vitamin K1 (phylloquinone), vitamin K2 (menaquinone) and vitamin $\mathrm{K} 3$ (menadione) are the three different forms of vitamin $\mathrm{K}$. These three forms are derivatives of naphthoquinone. Phylloquinone is found in plants, menaquinone is produced by the intestinal normal flora and menadione is a synthetic form. The main source of vitamin $\mathrm{K}$ is plants containing phylloquinone which includes green leafy vegetables like spinach, broccoli, cabbage, lettuce, etc., and soybean and canola oil (Nelson et al., 2008).

\section{Preventive roles of vitamins in COVID-19}

Vitamins play multiple roles in cellular metabolism and physiology. Along with their roles in growth, development and homeostasis they have been shown to strengthen immune system as discussed in previous section. In the next section, the applicability of vitamins in the management of COVID-19 has been discussed on the basis of scientific reports. A summary of the sources and roles played in COVID-19 management by various vitamins has been summarised in Table 1.

\subsection{Vitamin A}

The immune system remains active all the time and provides protection. However, during an infection the immune activity enhances which is accompanied by an increase in the production of immune and regulatory cells. These processes require higher metabolic and biosynthetic rate and an increased demand of the energy sources. Vitamins support the immune system by acting as cofactors to important biosynthetic enzymes or supporting the maturation of the immune cells (Calder, 2020). Vitamin A also participates in a number of activities associated with strengthening the immunity as mentioned above.

Due to the anti-inflammatory and antioxidant properties of vitamins (Zinder et al., 2019), clinical trials to find promising treatment for COVID-19 have been undertaken. Although, efficient treatment has not been found with clinical trials still in progress, the use of vitamin A along with other vitamins is recommended to reduce the risk and severity of the infection (Michienzi and Badowski, 2020). The association between vitamin intake and prevalence of respiratory complaints in adults in the UK was studied, and it was found that intake of vitamin $\mathrm{A}$ in diet or supplements controls the consequences of respiratory diseases. However, due to the limitations of the study, this cannot be extended to the respiratory complaints associated with COVID-19 (Almoosawi and Palla, 2020).

\subsection{Vitamin B}

B vitamins are essentials for the functioning of cell metabolism. A treatment with vitamin B complex may modulate cytokine/chemokine generation and mediate interaction with immune cells involved in pathophysiological pathways and inflammation. Thiamine (vitamin $B_{1}$ ), plays a key role on inflammation and immune response in both humans and rats, it inhibits inflammatory mediators and exert antiinflammatory effects through regulation of the arachidonic acid pathway in macrophages as well as suppression of the oxidative stress-induced activation of NF- $\mathrm{kB}$ (necrosis factor), in LPS-induced macrophage cell death and monocyte adhesion to endothelial cells. In brain, vitamin $B_{1}$ prevented and reduced neuronal cell death and neuroinflammation by down-regulation of the expression of proinflammatory mediators (cycloxygenase-2, lipoxygenase-2, TNF$\alpha$, IL-1), and deletion of CD40L-positive astrocytes and CD40positive microglia. In lung, the vitamin $\mathrm{B}_{1}$ deficiency has been identified in patients with pneumonia, the thiamine levels were negatively correlated with pneumonia patients (Shakoor et al., 2021). 
Table 1: Sources of vitamins and their roles in COVID-19 management

\begin{tabular}{|c|c|c|c|c|}
\hline Vitamin & Scientific name & Sources & Important role in COVID-19 & References \\
\hline Vitamin A & Retinol & $\begin{array}{l}\text { Whole milk, eggs, } \\
\text { fish liver oils, butter, } \\
\text { carrots, sweet potatoes }\end{array}$ & $\begin{array}{l}\text { Vitamin A demonstrates anti-inflammatory } \\
\text { and antioxidant properties. Hence, the effect } \\
\text { of vitamin A on patients suffering from } \\
\text { COVID-19 is being assessed. The intake of } \\
\text { vitamin A is recommended to reduce the } \\
\text { severity and risk of infection. }\end{array}$ & $\begin{array}{l}\text { Zinder et al. (2019); } \\
\text { Michienzi and } \\
\text { Badowski (2020) }\end{array}$ \\
\hline $\begin{array}{l}\text { Vitamin B } \\
\text { complex }\end{array}$ & $\begin{array}{l}\text { Thiamine (B1) } \\
\text { Riboflavin (B2) } \\
\text { Niacin (B3) } \\
\text { Pantothenic } \\
\text { acid (B5) } \\
\text { Pyridoxine (B6) } \\
\text { Biotin (B7) } \\
\text { Folate or 'folic } \\
\text { acid' (B9) Cyanoco- } \\
\text { balamin (B12) }\end{array}$ & $\begin{array}{l}\text { Milk, eggs, meat, beets, } \\
\text { spinach, fish, whole } \\
\text { grains and cereals, } \\
\text { banana, yeast }\end{array}$ & $\begin{array}{l}\text { B vitamins are essentials for the functioning } \\
\text { of cell metabolism. A treatment with vitamin } \\
\text { B complex may modulate cytokine/chemokine } \\
\text { generation and mediate interaction with } \\
\text { immune cells involved in pathophysiological } \\
\text { pathways and inflammation. Vitamin B } \\
\text { therapy helps to boost immune system, and } \\
\text { could therefore prevent or reduce damage of } \\
\text { COVID-19. }\end{array}$ & $\begin{array}{l}\text { Dos Santos (2020); } \\
\text { Shakoor et al. }(2021)\end{array}$ \\
\hline Vitamin $\mathrm{C}$ & Ascorbic acid & $\begin{array}{l}\text { Citrus fruits, guava } \\
\text { tomatoes potatoes }\end{array}$ & $\begin{array}{l}\text { Vitamin C exhibits immunomodulatory } \\
\text { properties by regulating the cytokine redox } \\
\text { signalling and inhibiting oxidative stress which } \\
\text { is important for the innate immune response to } \\
\text { viral respiratory infection. Injectable doses of } \\
\text { vitamin C in addition to standard treatment } \\
\text { shows significant reduction in inflammatory } \\
\text { parameters. An improvement in the quality of } \\
\text { oxygenation was observed when high doses of } \\
\text { vitamin C were given to patients with severe } \\
\text { COVID-19 infection. }\end{array}$ & $\begin{array}{l}\text { Abobaker } \text { et al. }(2020) \text {; } \\
\text { Cheng } \text { et al. }(2020) ; \\
\text { Hiedra et al. }(2020)\end{array}$ \\
\hline Vitamin D & Calciferol & $\begin{array}{l}\text { Mushrooms, egg yolk, } \\
\text { fish liver oils, fatty fish, } \\
\text { milk, butter }\end{array}$ & $\begin{array}{l}\text { Excess accumulation of angiotensin II leads to } \\
\text { increased severity of COVID- } 19 \text { infection. } \\
\text { Vitamin D supplementation ceases angiotensin } \\
\text { II accumulation. Vitamin D also inhibits renin } \\
\text { which results in inhibition of damage related } \\
\text { to myocardial infarction and ARDS in } \\
\text { COVID-19 patients. }\end{array}$ & $\begin{array}{l}\text { Hashemifesharaki and } \\
\text { Gharibzahedi (2020); } \\
\text { Bilezikian et al. (2020) }\end{array}$ \\
\hline Vitamin E & Tocopherol & $\begin{array}{l}\text { Wheat germ, eggs, } \\
\text { vegetable oil }\end{array}$ & $\begin{array}{l}\text { Cell-mediated and humoral immune responses } \\
\text { are affected in case of Vitamin E deficiency. } \\
\text { Increased oxidative stress, as observed in } \\
\text { COVID-19 patients, can be reduced with the } \\
\text { intake of vitamin E. There may also be an } \\
\text { increase in the efficacy of a vaccine against } \\
\text { COVID-19 in case of supplementation with } \\
\text { vitamin E. Selenium coupled with vitamin E } \\
\text { can reduce susceptibility to infection. } \\
\text { Additionally, the anti-inflammatory effect } \\
\text { of vitamin E on the gut microbiota can be } \\
\text { studied as oxidative stress is related to the } \\
\text { pathogenesis of COVID-19. }\end{array}$ & $\begin{array}{l}\text { Zabetakis et al. }(2020) \text {; } \\
\text { Jovic et al. }(2020) \text {; } \\
\text { Shakoor et al. }(2021) \text {; } \\
\text { Ferreira et al. }(2020)\end{array}$ \\
\hline Vitamin $\mathrm{K}$ & $\begin{array}{l}\text { Phylloquinone } \\
\text { (Vitamin K1) } \\
\text { Menaquinone } \\
\text { (Vitamin K2) } \\
\text { Menadione } \\
\text { (Vitamin K3) }\end{array}$ & $\begin{array}{l}\text { Green leafy vegetables, } \\
\text { soybean, canola oil }\end{array}$ & $\begin{array}{l}\text { Vitamin K-associated factors play an important } \\
\text { role in the progression of COVID-19 disease. } \\
\text { The deficiency of vitamin K is common in } \\
\text { COVID-19 patients. A comprehensive } \\
\text { assessment of the therapeutic potential } \\
\text { of vitamin } \mathrm{K} \text { has also been suggested. }\end{array}$ & $\begin{array}{l}\text { Anastasi et al. (2020); } \\
\text { Janssen } \text { et al. (2020); } \\
\text { Tutusaus } \text { et al. }(2020)\end{array}$ \\
\hline
\end{tabular}

A trial with vitamin $\mathrm{B}_{1}$ (200 mg every $12 \mathrm{~h}$ for 4 days), $\mathrm{C}$ (1.5 g every $6 \mathrm{~h}$ for 4 days), and hydrocortisone (50 mg every $6 \mathrm{~h}$ for 7 days then tapered over 3 days) showed a significant decrease hospital morbidity and mortality in patients with severe pneumonia (56\%) comparison to control group in patients with severe pneumonia (Kim et al.,
2018). Thus, since COVID-19 was found to be associated with pneumonia patients, moderate doses of Vitamin $\mathrm{B}_{1}$ supplementation might help to reduce lung inflammation and lung injury in novel COVID-19. Defects of the immune system and lower interferon gamma (IFN- $\gamma$ ) reported in severe COVID-19 patients have been 
previously linked with insufficient thiamine levels (Shakoor et al., 2021). Adequate thiamine may, therefore, augment interferon gamma levels, which correlated with lower viral load in bronchial aspirates and faster viral clearance in patients with COVID-19. The increased expression of interleukin 6 (IL-6) resultantly to riboflavin and nicotinamide deficiencies was also observed in severe COVID-19 patients (2.9 fold higher compared with noncomplicated disease) as an indicator of transition from mild to severe infection (MazurBialy and Pocheć, 2017).

The use of immunomodulatory, IL-6 pathway inhibitors are highly important point and therapeutic target for COVID-19 (Atal and Fatima, 2020). Based on this strategy, riboflavin and vitamin $B_{3}$ can be explored for their inhibitor potentials of COVID-19 by IL-6 blockade. Additionally, the orally supplementation with $500 \mathrm{mg} / \mathrm{kg}$ riboflavin showed its ability to reduce the in vivo IL-6 production (Menezes et al., 2017). Riboflavin exerts also a protective effect against SARS-CoV-2 disease, in combination with UVB radiation on human blood plasma. The treatment with riboflavin $(500 \mu \mathrm{mol} / \mathrm{l})$ and UV-B (Mirasol PRT system; (270-360 nm)) showed virucidal activity against SARS-CoV-2 in single-donor plasma units and in whole blood units, the viral titre was reduced by $4.79 \pm 0.15 \mathrm{log} /$ PFU and $3.30 \pm 0.26 \log \mathrm{PFU} / \mathrm{ml}$, respectively (Ragan et al., 2020). This system could reduce some of the risk of transfusion transmission of COVID-19 as well as pathogen-reduced blood products for critically ill patients with COVID-19 (Shakoor et al., 2021).

Vitamin $\mathrm{B}_{6}$ supplementation has been associated with alleviating symptoms of COVID-19, by regulating immune responses, reducing the production of pro-inflammatory cytokines, maintaining endothelial integrity and preventing hypercoagulability (Desbarats, 2020). The pyridoxine deficiency leads to the impairment of $T$ cell differentiation (Trakatellis et al., 1997). In viral COVID-19 infection, the $\mathrm{T}$ cells have been shown to play an important role in producing long-term immunological memory, following recovery from COVID19 and in clearing viral infection and reduced neutralizing antibody titers (Chen and Wherry, 2020). A supplementation, with Vitamin $\mathrm{B}_{6}$ could improve the survival and function of $\mathrm{T}$ cells and increase immune responsiveness of $\mathrm{T}$ cells (Sun et al., 2020). The administration of vitamin $B_{9}$ during pregnancy has been proposed to be a protective factor for COVID-19 (Acosta-Elias and EspinosaTanguma, 2020).

A folate supplementation was found to thwart COVID-19 disease, through the inactivation of furin crucial for SARS-CoV-2 host cell entry by cleavage of spike glycoprotein of SARS-CoV-2 at the S1/S2, and, therefore, promote high binding affinity to its angiotensinconverting enzyme 2 receptor ACE2 (Wu et al., 2020). While the inhibition of the viral 3-chymotrypsin-like cysteine protease (3CLpro) enzyme, which plays a key role in cleaving viral polyproteins into functional proteins, cuts the viral replication of SARS-CoV-2 (Li and Kang, 2020). Inhibition of SARS-CoV-2-3CL pro and SARS-CoV-2 - furin activities by the folic acid may provide a basis for design of anti-COVID-19 drugs (Cheng et al., 2020b; ul Qamar et al., 2020). A symptomatic similarity was found between vitamin $\mathrm{B}_{12}$ deficiency and SARS-CoV-2, both causes elevated oxidative stress and lactate dehydrogenase, hyperhomocysteinemia, coagulation cascade activation, central nervous system disorders, vasoconstriction and renal and pulmonary vasculopathies (dos Santos, 2020; Grangé et al., 2015; Sabry et al., 2020). A treatment with the methylcobalamin, the active form of vitamin $B_{12}$, decreased oxidative stress, act as an anti-inflammatory and analgesic agent, and can probably adjunct treatment for COVID-19 patients (dos Santos, 2020). Vitamin B therapy helps to boost immune system, and could therefore prevent or reduce damage of COVID-19.

\subsection{Vitamin C}

Results evaluating the benefit of the vitamin $\mathrm{C}$, hydrocortisone and thiamine combination for pneumonia management have indicated that the use of this combination improves chest radiological outcomes in patients with serious pneumonia and has the potential to decrease mortality. In addition, the vitamin $\mathrm{C}$ use was not associated with an elevated acute renal injury rate or reinfection (Boretti and Banik, 2020). From the aforementioned, there is potential usefulness of vitamin $\mathrm{C}$ in viral infections and perhaps the current COVID-19 situation.

COVID-19, as with all coronavirus respiratory syndrome, is generally manifested by fever and cough, which most commonly develop into inferior respiratory system diseases, with impaired clinical manifestations correlated with advanced age and preexisting health conditions. It is also characterized by expirations and the presence of pulmonary imagery traits (Bauer et al., 2020). It has been indicated that the COVID-19 mechanism is associated with cytokine storming and subsequent immunogenic damage. No treatment with a clearly demonstrated clinical benefit exists, although numerous pharmacological therapies are being used or considered for the treatment of COVID-19.

Vitamin $\mathrm{C}$ has been proven to exhibit immunomodulatory properties through the regulation of cytokine redox signaling in host defense cells and the inhibition of oxidative stress. These properties are an essential component of the innate immune response to viral respiratory infection. The reduction of reactive oxygen species (ROS) also helps to prevent ROS-induced lung damage (Abobaker et al., 2020). In the same context, it was indicated that vitamin $C$ can control the clarification of alveolar liquid through the improvement of the functionality of the pulmonary epithelial barrier by promoting the epigenetic and transcriptional aspect of the protein pathways that regulate the clarification of this liquid (Fisher et al., 2012). It has been evaluated that the effective use of different vitamin $\mathrm{C}$ injectable doses as an additive to standard treatment in a subject's series with moderate to severe COVID-19. They have found a substantial reduction in inflammatory parameters, in particular ferritin and Ddimer, and a decrease in $\mathrm{FiO}_{2}$ levels, with a mortality rate of $12 \%$ and a need for mechanical ventilation of $17.6 \%$ (Hiedra et al., 2020). It is also reported that high doses of vitamin $\mathrm{C}$ ranging from 2 to $10 \mathrm{~g}$ per day were provided to manage fifty patients with moderate to high severity COVID-19 over an 8 to 10 hour period by intravenous infusion (Cheng et al., 2020a). It was noted that the quality of oxygenation has greatly enhanced and that all affected individuals eventually recovered and they were discharged from the hospital. Recapitulating, the implication of vitamin C, especially when intravenously administered, in the treatment protocol of subjects with moderately to severely affected COVID-19 might have clinical efficacy.

\subsection{Vitamin D}

From December 2019 till date (08/05/2021), as per data available on WHO website, 155 million cases are reported and around 3 million deaths reported, and as more and more research on SARS-CoV-2 is 
done around 403 publications (PUBMED) on correlation of vitamin D with COVID-19 infection are published and 19,500 on Google Scholar. The major cause of severe COVID-19 infection and death are found to be cytokine storm (Meltzer et al., 2020), which occurs due to chemokines and proinflammatory cytokines. SARS-CoV-2 virus on entering airway multiplies very fast causing epithelial inflammation and trigger increase in production of proinflammatory cytokines and chemokines (Suvarna and Mohan, 2020). The different activities reported for vitamin D includes reduction in leukocyte count, neutrophils, mast cells, and monocytes also an increase in regulatory $\mathrm{T}$ cells and memory cells. The antimicrobial role of vitamin is also influenced by cationic host defense peptides (CHDP) (Pizzini et al., 2020). During COVID-19 infection in epithelial tissues of lungs occurs due to delayed increase in IFN $\alpha$ and $\beta$ (Class 1 interferon), leads to influx of inflammatory cells and also results in apoptosis of $\mathrm{T}$ cells (Weir et al., 2020). The severity of the infection occurs in the form of microvascular and alveolar barrier blockage, epithelial and endothelial apoptosis subsequently leads to alveolar oedema and vascular leak (Zemb et al., 2020).

Vitamin D is associated with innate and adaptive immunity in many studies. During many disease condition like tuberculosis, various granulomatous diseases, and sarcoidosis cells like dendritic synthesize 1, 25 2D (1, 25-dihydroxyvitamin D) from 25-OHD (25-hydroxy vitamin D) using enzyme CYP27B1 (1 $\alpha$-hydroxylase) (Zemb et al., 2020). Epithelial cells, "the first line of defense" also expresses CYP27B1 and vitamin D receptor complex with an action on the cathelicidin gene. Cathelicidin gene induces chemotaxis of neutrophils, proinflammatory cytokines, macrophages, and T cells (Casanova et al., 2020; Meltzer et al., 2020). It also promotes $\beta$-defensin, which recruit macrophages, NK cells (natural killer cells), and T cells via stimulated cytokines and chemokines. The activated defensins and cathelicidin by vitamin D block and suppress viral entry to the cell and reduce viral replication (Barlow et al., 2014). Vitamin D is also found to be involved in promoting autophagy. In this process, viral particles are encapsulated and digested by lysosome as antiviral immune response. 25-OHD and 1,25 2D reported to enhance LC3 (autophagy marker) (McElvaney et al., 2020). 1,25 2D promotes PI3KC3 and Beclin enzymes of autophagy, and also blocks mTOR pathways that inhibit autophagy. Although direct involvement of vitamin D in COVID-19 disease condition or in SARS-CoV-2 is not clear but it is found to be involved in HIV-1, influenza A, hepatitis C, wider virus, and rotavirus (Fara et al., 2020) (Figure 2).

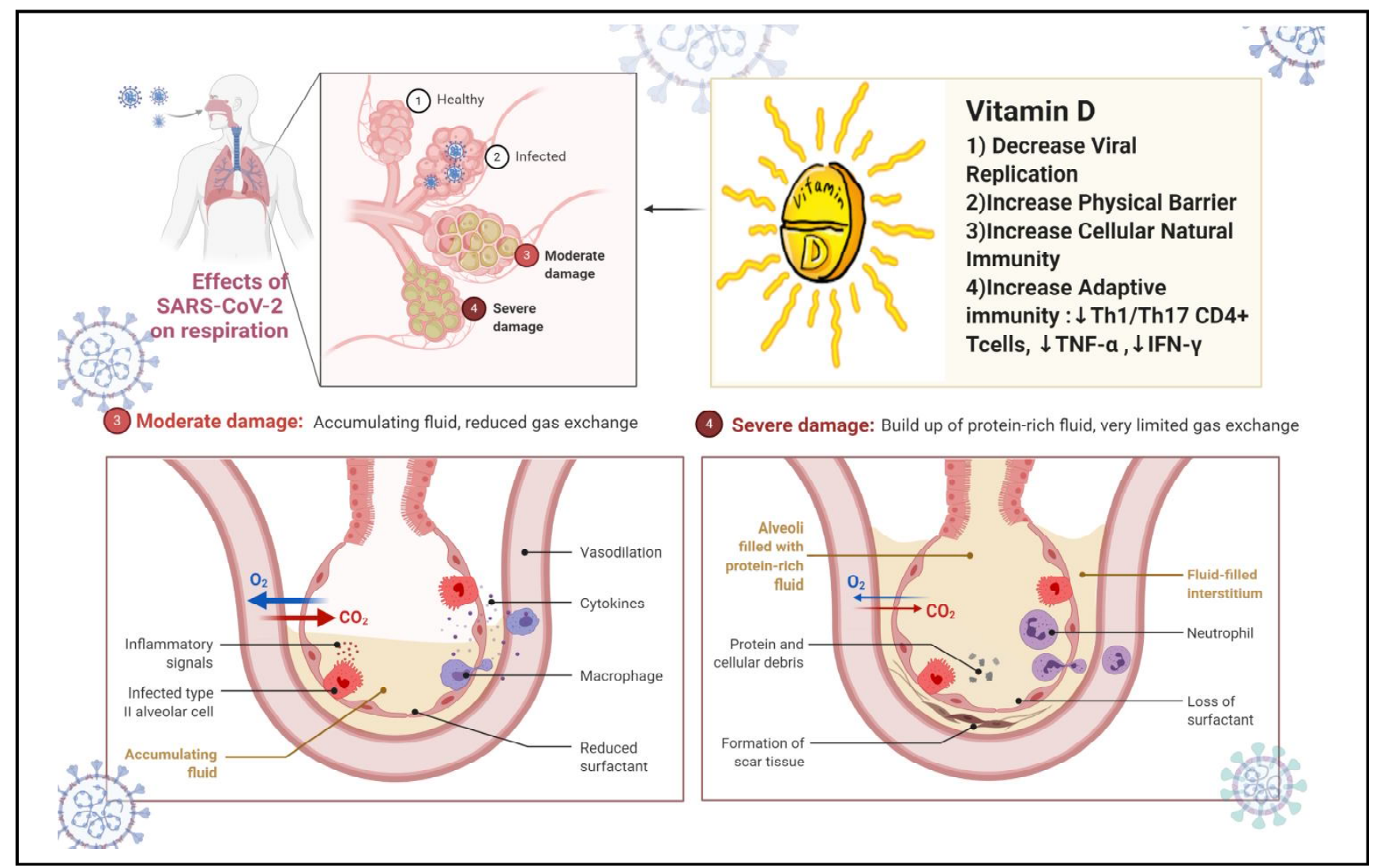

Figure 2: Effect of vitamin D on lungs and other immunity in case of SARS-CoV-2 infection.

\subsubsection{Exploring links between vitamin D deficiency and COVID-19}

Vitamin D deficiency and its corelation of many diseases were studied in many countries and on in different population around the world. Vitamin D in many studies is related with activation of immune cells, and production of AMPs that can inactivate influenza virus (Mercola et al., 2020). India is one of the countries with rapid spread and third highest mortality rate of COVID-19 is found to have more than $70 \%$ of the population with vitamin D deficiency. In an in vitro study, vitamin D deficiency is found related to acute respiratory distress syndrome (Steffen, 2020) and imbalance the expressions of members of the renin angiotensin aldosterone system (RAAS). It was observed 
that the effect of 25D concentration on different viral diseases like dengue, hepatitis B, HIV, respiratory syncytial viral infection, and influenza (Suvarna and Mohan, 2020).

The risk of viral infection reduces up to $27 \%$ with a supplement of $125 \mathrm{nmol} / \mathrm{l}$ (Gupta, 2014). An in vitro study on primary alveolar epithelial cells of murine and human demonstrated effect of vitamin D deficiency increases the severity of alveolar inflammation, hypoxia, and epithelial damage and ARDS (Zheng et al., 2020).

\subsubsection{Vitamin D and its role in COVID-19}

The mechanism of action of SARS-CoV-2 virus in lungs depends on interaction between spike protein of virus and ACE2 (angiotensinconverting enzyme) receptor present on the surface of type 2 pneumocyte cell, which are target of SARS-CoV-2 virus. This binding promotes activity of ACE1 resulting in increased production of angiotensin II resulting in severity of COVID-19 of patients. Surfactant protein A which controls the function of alveoli and gases exchange occurrence collapse when affected by SARS-CoV-2 virus is cleared by surfactant protein D in mice model also affects with concentration of $1 \alpha, 252 \mathrm{D}$. Vitamin D supplement in rat found to increase expression of ACE2 by metabolizing calcitriol (Evans and Lippman, 2020). On one hand, calcitriol induce synthesis of $\alpha-1$ antitrypsin, which helps in repair of lungs by $\mathrm{T}$ and $\mathrm{CD} 4$ cells and production of IL-10 but, its higher concentration can cause hypercalcemia (Hashemifesharaki and Gharibzahedi, 2020). Vitamin D supplement not only stops accumulation of angiotensin II but also inhibit renin, thus functions as potential inhibitor of damage related to ARDS, cardiac injury and myocardial infarction in COVID19 patients (Bilezikian et al., 2020).

\subsection{Vitamin E}

Recent studies suggest that supplementation of vitamins, in a higher dose than the recommended dietary allowance; to patients afflicted by COVID-19 can reduce the viral load of SARS-CoV-2 as well as period of hospitalisation associated with it (Shakoor et al., 2021). This effect is brought about by the antioxidant properties of vitamins which can improve the condition of the immune system and attenuate the development of ARDS (Jovic et al., 2020).

\subsubsection{Vitamin E: The immune system and mechanism of action against disease}

Vitamin E (a fat-soluble vitamin) forms the biological membranes as a lipid component and it includes a total of eight isoforms - four tocopherols $(\alpha-, \beta-, \gamma$, and $\delta$-tocopherols), and four tocotrienols $(\alpha-, \beta-, \gamma-$, and $\delta$-tocotrienols). However, these isoforms are not interconvertible and the only isoform that satisfies the vitamin $\mathrm{E}$ requirements of humans is $\alpha$-tocopherol. Primarily, $\alpha$-tocopherol is found in nuts like hazelnuts and almonds, avocados, green leafy vegetables, peanuts, sunflower seeds and fortified cereals. The absorption of vitamin $\mathrm{E}$ takes place in the small intestine whereas the liver regulates, metabolises and excretes it. Even though, the predominant biologically active isoform of vitamin $\mathrm{E}$ is $\alpha$-tocopherol, few studies have shown tocotrienols to have more potent antioxidant properties when tested on rat models to study neutralisation of peroxyl radicals and peroxidation of lipids. However, due to its lesser bioavailability, there is less focus on its research (Jovic et al., 2020).
Compared to other vitamins, vitamin $\mathrm{E}$ has the highest antioxidative potential (Ghosh et al., 2020). Vitamin E contains a chromanol ring from which it donates a hydrogen ion, thereby neutralising free radicals and reactive oxygen species (ROS). Metabolic processes taking place in the body release free radicals which react with polyunsaturated fatty acids present in the membrane of the cell and cause decomposition due to peroxidation. Vitamin $\mathrm{E}$ deficient in vitro and in vivo models show enhanced levels of lipid peroxidation. Patients afflicted by ARDS display an inverse correlation between vitamin $\mathrm{E}$ and plasma lipoperoxidase, as observed clinically (Jovic et al., 2020). Additionally, deficiency in vitamin $\mathrm{E}$ also aggravates the myocardial injury observed in mice infected with the RNA virus coxsackievirus B3. The severity of the infection was significantly increased in case of vitamin E or selenium deficiency (Zhang and Liu, 2020). Vitamin E can improve immune response by the mechanisms given below;

- Downregulation of prostaglandin E2 and cyclooxygenase-2 inhibition caused by reduction in the production of nitrogen oxide.

- The formation of immune synapse enhanced in naïve T cells and the initiation of signals of T-lymphocyte cells.

- Modulation of Type 1 T-helper cells and Type 2 T-helper cells (Th1/Th2) balance (BourBour et al., 2020; Jovic et al., 2020).

In addition to this, vitamin $\mathrm{E}$ can also cause immunomodulatory effects via protein kinase $\mathrm{K}$ ( $\mathrm{PKC}$ ). The proliferation of neutrophils, macrophages and monocytes is affected and there is a decrease the production of superoxide free radicals due to the inhibition of PKC (Jovic et al., 2020). There have been reports that have shown that the influenza virus period of infection can be decreased by supplementation of vitamin $E$. The results of a study suggest that a group treated with vitamin E, which was given $200 \mathrm{IU}$ of vitamin $\mathrm{E}$ per day, experienced lesser days with common cold than usual (BourBour et al., 2020).

\subsubsection{Vitamin E and COVID-19}

Recent investigations have suggested that a deficiency in vitamin $\mathrm{E}$ can affect both cell-mediated and humoral immune responses (Zabetakis et al., 2020). The immunosuppressed population such as people with chronic illnesses and the aged are more susceptible to many of the respiratory infections including COVID-19. The steady degeneration of the immune system with old age is known as "immunosenescence". Improved immune activity mediated by $\mathrm{T}$ lymphocyte cells relating to mitogens and interleukin-2 (IL-2), natural killer cell (NK) activity and neutrophil activity is attributed to vitamin $\mathrm{E}$ and has been observed to degrade with senescence. ARDS because of COVID-19 is driven by the underlying mechanism of oxidative stress. There is major lipid peroxidation resulting in failure of cell membranes due to this oxidative stress. The pathophysiology is characterised by pulmonary oedema, formation of hyaline membrane and diffuse alveolar damage in very serious conditions of this disease. The imbalance between antioxidants and oxidants can be rectified by ingestion of vitamin E. Superoxide production can also be reduced. Enhanced virulence of influenza virus, coxsackievirus and RNA viruses like COVID-19 has been observed in animal models with deficiency in vitamin E. Supplementation with vitamin E, in populations that are at a high risk of infection, may also increase the efficacy of a vaccine against COVID-19 as observed with increased titers of tetanus antibody (Jovic et al., 2020). 
The trace element selenium coupled with vitamin E has shown significant improvement in antioxidant defence. Studies have reported that there is an increase in viral pathogenicity and alteration of immune response in case of deficiency in either of these nutrients. In many Chinese provinces, it has been observed that there is an association between geographic levels of selenium and cure rates of COVID-19. Selenium and vitamin E reduce susceptibility to infection by acting via antioxidant pathways which results in an improvement in activity of NK cells, rise in secretion of IL-2 cytokines, improvement in responses of mitogenic lymphocytes and increase in the number of T-cells. It has also been observed that selenium and vitamin $\mathrm{E}$ can improve resistance to respiratory infections. Due to a wide range of available receptors, existence of varied tocopherols is more effective than the presence of only $\alpha$-tocopherol (Shakoor et al., 2021).

There have also been studies on effect of vitamins on the gut microbiota of humans. Interactions between a virus and the microbiota have been studied in various viral infections. For instance, surfactin is a surface molecule produced by bacteria and targets influenza A along with many other viruses. It may also disrupt the integrity of Coronavirus particles. In this context, it is probable that the gut microbiota influences the virulence of SARS-CoV-2 and SARS-CoV-2 can have a significant effect on the gut microbiota by encouraging dysbacteriosis and other such detrimental outcomes (Donati Zeppa et al., 2020). Supplementation with vitamin E can regulate the growth of microbiota beneficial to health such as the species of Bifidobacterium and Lactobacillus genera. Additionally, a study was performed which suggested that vitamin E coupled with selenium and retinoic acid can bring about an anti-inflammatory effect by reshaping the gut microbiota thereby alleviating inflammation of the mucosa in mice model of ileal pouchitis. It has also been observed that the Bacteroidetes percentage is increased and the Firmicutes percentage is decreased in relation to supplementation. Since, oxidative stress is related to the pathogenesis of COVID-19 and can cause major inflammation, the anti-inflammatory effect that vitamin $\mathrm{E}$ has on the gut microbiota can be studied. Further, research needs to be done on the impact of vitamin $\mathrm{E}$ on the gut microbiota of patients suffering from COVID-19 (Ferreira et al., 2020).

\subsection{Vitamin K}

The main functions of vitamin $\mathrm{K}$ are all related to the process of blood clotting. However, in a recent study, it was reported that vitamin K-associated factors play a significant role in the progression of severe acute respiratory syndrome coronavirus-2 (SARS-CoV-2) infection and COVID-19 disease. There is a subfamily in receptor tyrosine kinase (RTK) family known as TAM receptors. These receptors are known for their expression in immune cells. The ligands of the TAM receptors are protein S (PROS1) and growth-arrestspecific gene 6 (GAS6) which are vitamin K-dependent factors. In the SARS-CoV-2 infection and associated complications, the GAS6PROS1/TAM system has a notable role. In order to increase their infectivity, viruses use a strategy known as mimicry which is used by SARS-CoV-2 while infecting cells. The role of TAMs and the associated virus-host interactions are important in relation to COVID19. Therefore, treatment for these two diseases can be designed by targeting the receptor TAM (Tutusaus et al., 2020).

The relationship between vitamin K and COVID-19 patients has been studied (Anastasi et al., 2020). In this research, to investigate the diagnostic role of vitamin K deficiency in COVID-19 patient assessments have been chosen as 45 male and 17 female COVID-19 patient groups. The correlation between IL-6 levels and vitamin K status has been evaluated. In the male patient group observed, higher levels of IL-6 were found with severe vitamin K deficiency. The researcher is said that the two observations may be mechanically proposed. Interestingly, in patients admitted to the intensive care unit, the outcome of COVID-19 infection is known to be more severe in men than women, and they suggested that this may be associated with higher IL-6 and lower vitamin K levels in the male sex. In summary, the results of this study show that vitamin $\mathrm{K}$ deficiency is common in COVID-19 patients, and the deficiency is higher in men than in women. Additionally, the paper shows that vitamin $\mathrm{K}$ deficiency in male patients is associated with a higher level of IL-6 in the general circulation (Anastasi et al., 2020).

The deficiency of vitamin $\mathrm{K}$ in COVID-19 patients has been examined by Dofferhof et al. (2020) and the result of this study has been presented. The severe increase of Dp-uc MGP in COVID-19 patients indicates extrahepatic vitamin $\mathrm{K}$ deficiency associated with the poor outcome while the liver remains unaffected by procoagulant factor II. Disruption of activation of MGP and endothelial protein S caused shows the mechanism of extrahepatic vitamin $\mathrm{K}$ depletion caused by pneumonia leading to accelerated elastic fibre damage and thrombosis on COVID-19 patients. A clinical trial can assess whether vitamin $\mathrm{K}$ administration improves COVID-19 outcomes (Dofferhoff et al., 2020).

Another study revealing the relationship between vitamin $\mathrm{K}$ and COVID-19 has been made on the therapeutic potential of vitamin $\mathrm{K}$ by Janssen et al., (2020). It has been argued that the impact of the current crisis requires a comprehensive assessment of the therapeutic potential of vitamin $\mathrm{K}$ in COVID-19 pathogens for two main reasons. Unlike other treatment strategies, currently being developed for COVID-19, such as dexamethasone, vitamin K has no known adverse effects in non-VKA users. What's more, manufacturing is relatively simple and inexpensive, unlike other treatments such as redeliver or healing plasma. Taken together, this means that efficacy can be assessed quickly and inexpensively in clinical trials and easily applied if proven successful (Janssen et al., 2020).

\section{Recommendations and concerns of global and national agencies regarding vitamin supplements}

The COVID-19 was declared to be a pandemic by the World Health Organisation in 2020 (Hadizadeh, 2021). This pandemic has affected lifestyles, forcing everyone into self-isolation affecting physical and mental health of people around the world. Optimum nutrition is the key for the well-being of a person. Proper nutrition helps to alleviate various health consequences and helps in strengthening the immune system. Immune system plays a vital role in maintaining our health. Accordingly, to maintain our immune system a variety in dietary supplements is necessary such as micronutrients. Researchers also suggested that, combined supplementation with vitamins can be used as preventive and treatment therapy for COVID -19 (de Faria Coelho-Ravagnani et al., 2021).

Vitamins play a vital role in building up as well as maintenance of the immune system. Vitamin A helps in maintenance of mucosal lining of the mouth, respiratory tract and intestines. The recommended sources of vitamin A rich food are sweet potato, carrots, mango, papaya, apricots and eggs. Vitamin D has played an important role during the COVID-19 pandemic. Vitamin D induces the expression of ACE2 
receptor which further helps in regulation of the immune system (Hadizadeh, 2021). Vitamin D has been experimentally proved to reduce replication of respiratory viruses.

Micronutrients are important for health and maintains proper immune system, but there are no guidelines for the supplementation of micronutrients including vitamins either to prevent or cure COVID19. A well-balanced diet is advised to include fresh fruits, vegetables and animal source foods to fulfil the micronutrient requirement of an individual (WHO, 2021). However, due to lockdown imposed in various parts of the world during COVID-19 pandemic; if the person is exclusively spending more time indoors with little or no sun exposure and they are already having low or marginal vitamin D concentration are recommended to take supplement of 200-600 IU (according to age) (WHO, 2021). Vitamin D can be directly obtained from the diet or synthesized by skin via direct exposure to sunlight.

The panel of Public Health England (PHE), and the Scientific Advisory Committee on Nutrition (SACN), NICE (National Institute for Health and Care Excellence) in collaboration studied the relation of vitamin D to COVID-19 and said that there is not enough evidence to support role of Vitamin D to reduce or treat COVID-19 (NICE, 2020). The micronutrient supplementation programmes for pregnant women and young children should be continued during COVID-19. However, the routine or planned campaigns for micronutrient supply could be postponed/suspended or may be re-planned as the conditions improve (Food and Agricultural Organization of the United Nations, 2020).

To prevent or treat COVID-19 dietary supplements are not advised, the effect of few vitamins and minerals is observed to boost the immune system efficiency to fight infectious diseases, also effective during inflammation as well as swelling. Sometimes excess intake of dietary supplements shows unwanted serious effects like before surgery or if a person has certain health conditions (CDC, 2020).

For preschool children, Global Alliance for Vitamin A (GAVA), with the help of campaigns via routine health and nutritional services provides guidance of consensus statement for vitamin A supplementation during COVID-19 pandemic. As there is no evidence related to high-dose of vitamin A supplementation (VAS) is successful in treating COVID-19 or reducing the severity of the illness, VAS is particularly necessary for susceptible young children during an infectious disease outbreak. For the children aged between 6 to 59 months, either suspected or have confirmed COVID-19 infection belongs to the country of vitamin A deficiency (VAD) should continue to receive twice-yearly VAS as it remains an essential health and nutrition intervention (GAVA, 2020).

\section{Conclusion}

The COVID-19 pandemic situation has caused loss of millions of lives since its outbreak and has affected the socioeconomic status of almost every individual. Researchers and health experts have been trying their best to control this disease at the earliest to prevent the loss of lives. Several vaccines have been tested and approved with good success rate. Apart from proper medications, nutritional requirements are also being suggested by global health agencies to prevent the rapid spread and adverse health effects of COVID19.Vitamins show great importance in managing many conditions including viral infections. Direct and indirect evidence have been reported in the literature regarding the role of vitamins in the prevention of viral infections. Although, these reports seem to be quite useful in the health management pre- and during COVID-19 infection, global agencies and health experts have become concerned about the indiscriminate usage of these vitamins in the prevention especially in the absence of concrete scientific data.

\section{Conflict of interest}

The authors declare that there are no conflicts of interest relevant to this article.

\section{References}

Abobaker, A.; Alzwi, A. and Alraied, A.H.A. (2020). Overview of the possible role of vitamin C in management of COVID-19. Pharmacol Rep., pp: $1-12$.

Acosta-Elias, J. and Espinosa-Tanguma, R. (2020). The folate concentration and/or folic acid metabolites in plasma as factor for COVID-19 infection. Front Pharmacol., 11:1062.

Almaghaslah, D.; Kandasamy, G.; Almanasef, M.; Vasudevan, R. and Chandramohan, S. (2020). Review on the coronavirus disease (COVID 19) pandemic: Its outbreak and current status. Int. J. Clin. Pract., 74(11):e13637.

Almoosawi, S. and Palla, L. (2020). Association between vitamin intake and respiratory complaints in adults from the UK National Diet and Nutrition Survey years 1-8. BMJ Nutrition, Prevention and Health, bmjnph-2020-000150.

Amin, S.A. and Jha, T. (2020). Fight against novel coronavirus: A perspective of medicinal chemists. Eur. J. Med. Chem., 11:2559.

Anastasi, E.; Ialongo, C.; Labriola, R.; Ferraguti, G.; Lucarelli, M. and Angeloni, A. (2020). Vitamin K deficiency and COVID-19. Scand. J. Clin. Lab Invest, 80(7):525-527.

Atal, S. and Fatima, Z (2020). IL-6 inhibitors in the treatment of serious COVID-19: A promising therapy, Pharmaceut. Med., 34(4):223-231.

Backer, J.A.; Klinkenberg, D. and Wallinga, J. (2020). Incubation period of 2019 novel coronavirus (2019-nCoV) infections among travellers from Wuhan, China, 20-28 January 2020. Eurosurveillance, 25(5): 2000062 .

Barlow, P.G.; Findlay, E.G.; Currie, S.M. and Davidson, D.J. (2014). Antiviral potential of cathelicidins. Future Microbiology, 9(1):55-73.

Bauer, S.R.; Kapoor, A.; Rath, M. and Thomas, S.A. (2020). What is the role of supplementation with ascorbic acid, zinc, vitamin $\mathrm{D}$, or $\mathrm{N}$ acetylcysteine for prevention or treatment of COVID-19, Cleve Clin. J. Med., https://doi.org/10.3949/ccjm.87a.ccc046.

Bhat, E.A; Khan, J.; Sajjad, N.; Ali, A.; Aldakeel, F. M.; Mateen, A.; Alqahtani, M. S.and Rabbani, S. (2021). SARS-CoV-2: Insight in genome structure, pathogenesis and viral receptor binding analysis: An updated review, International Immunopharmacology, 95(63):107493.

Bilezikian, J.P.; Bikle, D.; Hewison, M.; Lazaretti-Castro, M.; Formenti, A.M.; Gupta, A.; Madhavan, M.V.; Nair, N.; Babalyan, V. and Hutchings, N. (2020). Mechanisms in endocrinology: Vitamin D and COVID-19. European Journal of Endocrinology, 183(5):R133-R147.

Boretti, A. and Banik, B.K. (2020). Intravenous vitamin C for reduction of cytokines storm in acute respiratory distress syndrome. Pharma. Nutrition: 100190 .

BourBour, F.; Mirzaei Dahka, S.; Gholamalizadeh, M.; Akbari, M.E.; Shadnoush, M.; Haghighi, M.; Taghvaye-Masoumi, H.; Ashoori, N. and Doaei, S. (2020). Nutrients in prevention, treatment, and management of viral infections; special focus on Coronavirus. Arch Physiol Biochem., pp: $1-10$. 
Calder, P.C. (2020). Nutrition, immunity and COVID-19. BMJ Nutrition, Prevention and Health, 3(1):74.

Casanova, V.; Sousa, F.H.; Shakamuri, P.; Svoboda, P.; Buch, C.; D'Acremont, M.; Christophorou, M.A.; Pohl, J.; Stevens, C. and Barlow, P.G. (2020). Citrullination alters the antiviral and immunomodulatory activities of the human cathelicidin LL-37 during rhinovirus infection. Frontiers in Immunology, 11:85.

CDC. (2020). Food and coronavirus disease 2019 (COVID-19).

Chen, Z. and Wherry, E.J. (2020). T cell responses in patients with COVID-19. Nature Reviews Immunology, 20(9):529-536.

Cheng, R.Z;; Kogan, M. and Davis, D. (2020a). Ascorbate as prophylaxis and therapy for COVID-19: Update from shanghai and US medical institutions. Global Advances in Health and Medicine, 9: 2164956120934768

Cheng, Y.W.; Chao, T.L.; Li, C.L.; Chiu, M.F.; Kao, H.C.; Wang, S.H.; Pang, Y.H.; Lin, C.H.; Tsai, Y.M. and Lee, W.H. (2020b). Furin inhibitors block SARS-CoV2 spike protein cleavage to suppress virus production and cytopathic effects. Cell Reports, 33(2):108254.

Cohen, J. (2020). Wuhan seafood market may not be source of novel virus spreading globally. Science, pp:10.

Correa-Rodríguez, M.; Gómez-Urquiza, J.L.; Medina-Martínez, I.; GonzálezJiménez, E.; Schmidt-RioValle,J. and Rueda-Medina, B. (2020). Low intake of vitamins $\mathrm{C}$ and A are associated with obesity in early adulthood. Int. J. Vitam. Nutr. Res., 8(3):381-385.

De Faria Coelho-Ravagnani, C.; Corgosinho, F.C.; Sanches, F.L.F.Z.; Prado, C.M.M.; Laviano, A. and Mota, J.F. (2021). Dietary recommendations during the COVID-19 pandemic. Nutr. Rev., 79(4):382-393.

Desbarats, J. (2020). Pyridoxal 5'-phosphate to mitigate immune dysregulation and coagulopathy in COVID-19.

Dofferhoff, A.S.M.; Piscaer, I.; Schurgers, L.J.; Visser, M.P.J.; van den Ouweland, J.M.W.; de Jong, P.A.; Gosens, R.; Hackeng, T.M.; van Daal, H.; Lux,P.; Maassen, C.,; Karssemeijer, E.G.A.; Vermeer, C.; Wouters, E.F.M.; Kistemaker, L.E.M.; Walk, J. and Janssen, R. (2020). Reduced vitamin K status as a potentially modifiable risk factor of severe COVID-19. Clin. Infect. Dis., doi: $10.1093 / \mathrm{cid} / \mathrm{ciaa} 1258$.

Donati Zeppa, S.; Agostini, D.; Gervasi, M.; Annibalini, G; Amatori, S.; Ferrini, F.; Sisti, D.; Piccoli, G.; Barbieri, E. and Sestili, P. (2020). Mutual interactions among exercise, sport supplements and microbiota. Nutrients, 12(1): 17.

Dos Santos, L.M.J. (2020). Can vitamin B12 be an adjuvant to COVID-19 treatment, GSC Biological and Pharmaceutical Sciences, 11(3):001005

Escher Jr, A.R. (2020). An ounce of prevention: Coronavirus (COVID-19) and mass gatherings. Cureus, 12(3).

Evans, R.M. and Lippman, S.M. (2020). Shining light on the COVID-19 pandemic: A vitamin D receptor checkpoint in defense of unregulated wound healing. Cell Metabolism, Review: 10(1):1-10.

Fara, A.; Mitrev, Z; Rosalia, R.A. and Assas, B.M. (2020). Cytokine storm and COVID-19: A chronicle of pro-inflammatory cytokines. Open Biology, 10(9):200160.

Ferreira, C.; Viana, S.D. and Reis, F. (2020). Gut microbiota dysbiosis-immune hyperresponse-inflammation triad in coronavirus disease 2019 (COVID-19): Impact of pharmacological and nutraceutical approaches. Microorganisms, 8(10). doi:10.3390/microorganisms 8101514

Fisher, B.J.; Kraskauskas, D.; Martin, E.J.; Farkas, D.; Wegelin, J.A.; Brophy, D. Ward, K.R.; Voelkel, N.F. and Natarajan, R. (2012). Mechanisms of attenuation of abdominal sepsis induced acute lung injury by ascorbic acid. American Journal of Physiology-Lung Cellular and Molecular Physiology.
Food and Agricultural Organization of the United Nations, U.U.N.C.s.F., WFP (World Food Programme) and WHO (World Health Organization). (2020). Joint statement on nutrition in the context of the COVID-19 pandemic in Asia and the Pacific, April 17, 2020.

FowlerIII,A.A.; Kim, C.; Lepler, L.; Malhotra, R.; Debesa, O.; Natarajan, R.; Fisher, B.J.; Syed, A.; DeWilde, C. and Priday, A. (2017). Intravenous vitamin C as adjunctive therapy for enterovirus/rhinovirus induced acute respiratory distress syndrome. World Journal of Critical Care Medicine, 6(1):85

FSSAI. (2020). Eat Right During COVID-19: Food hygiene, safety and nutrition guidelines for consumers to prevent the spread of coronavirus, pp:14-20.

Furuya, A.; Uozaki, M.; Yamasaki, H.; Arakawa, T.; Arita, M. and Koyama, A.H. (2008). Antiviral effects of ascorbic and dehydroascorbic acids in vitro. Int. J. Mol. Med., 22(4):541-545.

GAVA. (2020). Universal vitamin a supplementation for preschool-aged children in the context of COVID-19: GAVA consensus statement.

Ghosh, N.; Das, A. and Khanna, S. (2020). Vitamin E: Tocopherols and tocotrienol and their role in health and disease, Essential and toxic trace elements and vitamins in human health. Elsevier, pp:283293.

Gorji, A. and Ghadiri, M.K. (2020). The potential roles of micronutrient deficiency and immune system dysfunction in COVID-19 pandemic. Nutrition, pp:111047.

Grangé, S.; Bekri, S.; Artaud-Macari, E.; Francois, A.; Girault, C.; Poitou, A.L.; Benhamou, Y.; Vianey-Saban, C.; Benoist, J.F. and Châtelet, V. (2015). Adultonset renal thrombotic microangiopathy and pulmonary arterial hypertension in cobalamin C deficiency. The Lancet, 386(9997): 1011-1012.

Gupta, A. (2014). Vitamin D deficiency in India: Prevalence, causalities and interventions. Nutrients, 6(2):729-775

Hadizadeh, F. (2021). Supplementation with vitamin D in the COVID-19 pandemic, Nutr. Rev., 79(2):200-208

Hashemifesharaki, R. and Gharibzahedi, S.M.T. (2020). Future nutrient-dense diets rich in vitamin D: A new insight toward the reduction of adverse impacts of viral infections similar to COVID-19. Nutrire, 45(2): $1-3$.

Hiedra, R.; Lo, K.B.; Elbashabsheh, M.; Gul, F.; Wright, R.M.; Albano, J.; Azmaiparashvili, Z. and Patarroyo Aponte, G. (2020). The use of IV vitamin C for patients with COVID-19: A case series. Expert Rev Anti Infect Ther., 18(12):1259-1261.

Hui, D.S.; Azhar, E.I.; Madani, T.A.; Ntoumi, F.; Kock, R.; Dar, O.; Ippolito, G.; Mchugh, T.D.; Memish, Z.A. and Drosten, C. (2020). The continuing 2019nCoV epidemic threat of novel coronaviruses to global healthThe latest 2019 novel coronavirus outbreak in Wuhan, China. Int. J. Infect. Dis., 91:264-266.

Janssen, R.; Visser, M.P.; Dofferhoff, A.S.; Vermeer, C.; Janssens, W. and Walk, J. (2020). Vitamin K metabolism as the potential missing link between lung damage and thromboembolism in Coronavirus disease 2019. Br. J. Nutr., 1-8.

Jayawardena, R.; Sooriyaarachchi, P.; Chourdakis, M.; Jeewandara, C. and Ranasinghe, P. (2020). Enhancing immunity in viral infections, with special emphasis on COVID-19: A review, diabetes and metabolic syndrome: Clinical Research and Reviews, 14(4):367-382.

Jovic, T.H.; Ali, S.R.; Ibrahim, N.; Jessop, Z.M.; Tarassoli, S.P.; Dobbs, T.D.; Holford, P. and Thornton, C.A., Whitaker, I.S. (2020). Could vitamins help in the fight against COVID-19, Nutrients, 12(9):25-50.

Kim, H.; Jang, M.; Kim, Y.; Choi, J.; Jeon, J.; Kim, J.; Hwang, Y.i.; Kang, J.S. and Lee, W.J. (2016). Red ginseng and vitamin C increase immune cell activity and decrease lung inflammation induced by influenza $\mathrm{A}$ virus/H1N1 infection. J. Pharm Pharmacol., 68(3):406-420. 
Kim, W.Y.; Jo, E.J.; Eom,J.S.; Mok,J.; Kim, M.H.; Kim,K.U.; Park, H.K.; Lee, M.K. and Lee, K. (2018). Combined vitamin C, hydrocortisone, and thiamine therapy for patients with severe pneumonia who were admitted to the intensive care unit: Propensity score-based analysis of a beforeafter cohort study. J. Crit. Care, 47:211-218.

Lalchhandama, K. (2020). The chronicles of coronaviruses: the electron microscope, the doughnut, and the spike.

Li, Q. and Kang, C. (2020). Progress in developing inhibitors of SARS-CoV2 3C-like protease. Microorganisms, 8(8):1250.

Mazur-Bialy, A.I. and Pocheć, E. (2017). Vitamin B2 deficiency enhances the pro-inflammatory activity of adipocyte, consequences for insulin resistance and metabolic syndrome development. Life Sci., 178:9-16.

McElvaney, O.J.; McEvoy, N.L.; McElvaney, O.F.; Carroll, T.P.; Murphy, M.P.; Dunlea D.M.; Ní Choileáin, O.; Clarke, J.; O'Connor, E. and Hogan, G. (2020) Characterization of the inflammatory response to severe COVID19 illness. American Journal of Respiratory and Critical Care Medicine, 202(6):812-821.

McIntosh, K.; Hirsch, M. and Bloom, A. (2020). Coronavirus disease 2019 (COVID-19): Epidemiology, virology, and prevention. Lancet Infect. Dis., 1:2019-2020.

Meltzer, D.O.; Best, T.J.; Zhang, H.; Vokes, T.; Arora, V. and Solway, J. (2020) Association of vitamin D status and other clinical characteristics with COVID-19 test results. JAMA network open; 3(9):e2019722e2019722.

Menezes, R.R.; Godin,A.M.; Rodrigues, F.F.; Coura, G.M.; Melo, I.S.; Brito,A.M.S.; Bertollo, C.M.; Paulino, T.P.; Rachid, M.A. and Machado, R.R. (2017) Thiamine and riboflavin inhibit production of cytokines and increase the anti-inflammatory activity of a corticosteroid in a chronic model of inflammation induced by complete Freund's adjuvant. Pharmacol. Rep., 69(5):1036-1043.

Mercola, J.; Grant, W.B. and Wagner, C.L. (2020). Evidence regarding vitamin D and risk of COVID-19 and its severity. Nutrients, 12(11):3361.

Michienzi, S.M. and Badowski, M.E. (2020). Can vitamins and/or supplements provide hope against coronavirus, Drugs in Context, 9.

Nelson, D.L.; Lehninger, A.L. and Cox, M.M.(2008). Lehninger principles of biochemistry. Macmillan.

NICE, N.I.f.H.a.C.E. (2020). Public Health England (PHE), and the Scientific Advisory Committee on Nutrition (SACN) publish rapid COVID19 guidance on vitamin D.

Organization, W.H. (2020a). Laboratory testing for 2019 novel coronavirus (2019-nCoV) in suspected human cases: interim guidance, 14 January 2020: World Health Organization.

Organization, W.H. ( 2020b). World Health Organization coronavirus disease (COVID-19) dashboard.

Paramanya, A.; Padgaonkar, A. and Ali, A. (2021). Detection of coronavirus (SARS-CoV-2) using antibodies. In: COVID-19 Pandemic and Environmental ImplicationsSinha, V.S. (Ed.). Red'shine Publications Pvt. Ltd. India, pp:181-194

Pauling, L. (1971). Vitamin C and common cold. JAMA, 216(2):332-332.

Pizzini, A.; Aichner, M.; Sahanic, S.; Böhm, A.; Egger, A.; Hoermann, G.; Kurz, K.; Widmann, G.; Bellmann-Weiler, R., and Weiss, G. (2020). Impact of vitamin d deficiency on COVID-19: A prospective analysis from the CovILD registry. Nutrients, 12(9):2775.
Ragan, I.; Hartson, L.; Pidcoke, H.; Bowen, R. and Goodrich, R. (2020). Pathogen reduction of SARS-CoV-2 virus in plasma and whole blood using riboflavin and UV light. PLoS One, 15(5):e0233947.

Sabry, W.; Elemary, M.; Burnouf, T.; Seghatchian, J. and Goubran, H. (2020). Vitamin B12 deficiency and metabolism-mediated thrombotic microangiopathy (MM-TMA). Transfus. Apher. Sci., 59(1):102717.

Shakoor, H.; Feehan, J.; Mikkelsen, K.; Al Dhaheri, A.S.; Ali, H.I.; Platat, C.; Ismail, L.C.; Stojanovska, L.and Apostolopoulos, V. (2021). Be well: A potential role for vitamin B in COVID-19. Maturitas, 144:108-111.

Sun, J.; Zhuang, Z.; Zheng, J.; Li, K.; Wong, R.L.Y.; Liu, D.; Huang, J.; He, J.; Zhu,A. and Zhao, J. (2020). Generation of a broadly useful model for COVID19 pathogenesis, vaccination, and treatment. Cell, 182(3):734-743.

Suvarna, V.R. and Mohan, V. (2020). Vitamin D and its role in coronavirus disease 2019 (COVID-19). Journal of Diabetology, 11(2):71.

Trakatellis, A.; Dimitriadou, A. and Trakatelli, M. (1997). Pyridoxine deficiency: new approaches in immunosuppression and chemotherapy. Postgrad Med. J., 73(864):617-622

Tutusaus, A.; Marí, M.; Ortiz-Pérez, J.T.; Nicolaes, G.A.; Morales, A. and García de Frutos, P. (2020). Role of Vitamin K-Dependent Factors Protein S and GAS6 and TAM Receptors in SARS-CoV-2 Infection and COVID-19Associated Immunothrombosis. Cells, 9(10):2186.

Ul Qamar, M.T.; Alqahtani, S.M.; Alamri, M.A. and Chen, L.L. (2020). Structural basis of SARS-CoV-2 3CLpro and anti-COVID-19 drug discovery from medicinal plants. Journal of Pharmaceutical Analysis, 10(4):313319.

Van Regenmortel, M.H.; Fauquet, C.M.; Bishop, D.H.; Carstens, E.; Estes, M.; Lemon, S.; Maniloff, J.; Mayo, M.; McGeoch, D. and Pringle, C. (2000). Virus taxonomy: classification and nomenclature of viruses. Seventh report of the International Committee on Taxonomy of Viruses. Academic Press.

Weir, E.K.; Thenappan, T.; Bhargava, M. and Chen, Y. (2020). Does vitamin D deficiency increase the severity of COVID-19, Clinical Medicine, 20(4): 107.

WHO. (2021). https://www.who.int/news-room/q-a-detail/coronavirusdisease-covid-19-food-safety-and-nutrition.

Wu, C.; Zheng, M.; Yang, Y.; Gu, X.; Yang, K.; Li, M.; Liu, Y.; Zhang, Q.; Zhang, P. and Wang, Y. (2020). Furin: A Potential Therapeutic Target for COVID19. Science, 23(10):1016-1042.

Zabetakis, I.; Lordan, R.; Norton, C. and Tsoupras, A. (2020). COVID-19: the inflammation link and the role of nutrition in potential mitigation. Nutrients, 12(5):1466

Zemb, P.; Bergman, P.; Camargo, C.A.; Cavalier, E.; Cormier, C.; Courbebaisse, M.; Hollis, B.; Joulia, F.; Minisola, S. and Pilz, S. (2020). Vitamin D deficiency and the COVID-19 pandemic. J. Glob. Antimicrob. Resist, 22:133134.

Zhang, L. and Liu, Y. (2020). Potential interventions for novel coronavirus in China: A systematic review. J. Med. Virol., 92(5):479-490. doi: 10.1002/jmv.25707.

Zheng, S.; Yang, J.; Hu, X.; Li, M.; Wang, Q.; Dancer, R.C.; Parekh, D.; Gao-Smith, F.; Thickett, D.R. and Jin, S. (2020). Vitamin D attenuates lung injury via stimulating epithelial repair, reducing epithelial cell apoptosis and inhibits TGF- $\beta$ induced epithelial to mesenchymal transition. Biochemical Pharmacology, 177:113955.

Zinder, R.; Cooley, R.; Vlad, L.G. and Molnar, J.A. (2019). Vitamin A and wound healing. Nutr. Clin. Pract., 34(6):839-849.

Zoya Shaikh, Priya Sundarrajan, Lekha Bhagtaney, Sadaf Zehra, Kamal Fatima Zahra, Boubakeur Badra, Belkis

Muca Yigit, Nimisha Patel, Hina Alim, Johra Khan and Ahmad Ali (2021). Applicability of vitamins in the management of COVID-19: Ann. Phytomed., Volume10, Special Issue1 (COVID-19): S65-S76. http://dx.doi.org/ 10.21276/ap.covid19.2021.10.1.7 